\title{
Gossip Girls in a Transmedia World: The Sexual and Technological Anxieties of Integral Reality
}

\author{
Kim Toffoletti
}

The proliferation of sexualised imagery of children and adolescents - especially girls - within media and advertising has elicited considerable public debate and academic discussion within Australia and overseas. Within these debates, girls are commonly configured as being 'at risk', that is, in danger of being sexualised, objectified and exploited. They are said to be in danger of growing up believing that popularity and success are tied to sexual appeal (Durham 2008; Reist 2008; Rush and La Nauze 2006). Books for young people are not exempt from these critiques, with children's literature implicated in the agendas of mainstream consumer culture (Kline 1993). A case in point is Cecily von Ziegesar's hugely popular Gossip Girl series, which has come under fire, most notably by American feminist Naomi Wolfe (2006) in a review essay for the New York Times. Wolfe criticises the books, and others like them, for fostering the sexualisation of young women through the championing of sex, shopping and status as the pathways to social approval and personal fulfillment for teenage girls. While acknowledging an established history of texts that grapple with the dilemmas of adolescence - including themes of sexual exploration and identification - Wolfe insists that these newer versions of the genre are not in keeping with 'the frank sexual exploration found in a Judy Blume novel', but instead present us with 'teenage sexuality via Juicy Couture, blasé and entirely commodified' (Wolfe 2006).

The idea that texts are directly responsible for creating real world meanings and practices of sexuality is a pervasive position in mainstream discourse, despite research demonstrating that young adults have the potential for agency in negotiating, subverting and resisting dominant representations of sex and gender. While much of the scholarly literature on teen girls and the mass media recognises that young women are often exposed to highly sexualised depictions of femininity in a globalised media landscape, their critical focus extends to how girls negotiate such messages (Brown, Steele \& Walsh-Childers 2002; Hall \& Bishop 2007; Kearney 2006; Mazzarella \& Pecora 1999). This research brings to the fore the multiple and diverse nature of textual production, dissemination and reception, which raises the possibility that alternative models of femininity beyond the sex and shopping stereotype promulgated by many mainstream media outlets are available for young women.

In contrast to studies that are primarily concerned with examining how the content of popular texts and their circulation 'oppress' or 'empower' girls, this article seeks to assess the extent to which textual form contributes to the moral panics that flow from claims that girls are being rampantly sexualised in media representations. In this respect my analysis detours from approaches that rely on critical textual readings. I consider instead how the medium itself-books, television, the Internet - has the potential to shape perceptions of, and responses to, cultural imaginings of young women's sexuality. This article proposes that the blurring of the distinction between 'online' and 'offline' environments in the Gossip Girl franchise complicates conventional understandings of 'reality', and in turn, how 'real world' meanings of female sexuality might be discussed in the context of what Jean Baudrillard has termed 'integral reality' (2005a). Baudrillard(2005b, p.2) describes integral reality as a 'kind of ultra reality that puts an end to both reality and illusion', associating integral reality with a western cultural preoccupation with hypervisible, immediately accessible, increasingly immersive forms of information, data and text. It is within this context that I evaluate how cultural anxieties around the sexualisation of young women are fuelled by the transparency, proliferation and extensive circulation of popular texts in an age typified by transmedia experiences.

\section{Gossip Girl and Post-feminism}

For the uninitiated, Gossip Girl is a teen-fiction series comprising 11 novels and a prequel. The narrative follows the lives of a group of affluent teenagers from New York City's Upper East Side. We follow the antics of these privileged teens - their loves, lives, shopping and other bad habits - by means of a blog written by Gossip Girl, after whom the series is titled. The blogger is anonymous and omnipresent, regularly posting on the movements of the main characters - mean girl brunette Blair Waldorf, her best friend-turned-nemesis Serena Van Der Woosen, and their occasional shared love interest Nate Archibald. Completing this posse of friends is the rich and sleazy Chuck Bass and the brother and sister duo of Dan and Jenny Humphrey, 
who are relative outsiders in this privileged group. While the siblings attend the same elite private schools as their wealthy peers, they do not live in a penthouse or have 'unlimited access to money' like the other characters do (von Ziegesar 2003, p.3). Rather, the reader is informed that the Humphreys are part of a left-leaning, creative class. For example, early in the series we are told that Jenny and Dan's father is an 'infamous editor of lesser-known beat poets' (von Ziegesar 2003, p.49).

Certain aspects of the Gossip Girl novels position them within a genealogy of post-feminist texts - films, books, magazines and television programs characterised by a model of young womanhood that is empowered, successful, entitled, independent, socially mobile and free to choose her destiny (McRobbie 2007, p.270; Harris 2004, p.16). With its 'post' prefix, the term post-feminism implies the phase after feminism where battles for equality have been won and women are now reaping the benefits of a new gender regime (McRobbie 2004, p.255). The attributes associated with the post-feminist girl are often realised through consumption, both material and sexual, which appear as central features of post-feminist orthodoxy. These features also appear throughout the Gossip Girl storylines, which frequently link sex and consumer goods, as suggested in the following excerpt from the first novel in the series:
When Serena woke up a little while later, Chuck had changed the channel to MTV2 and was singing along loudly to Jay-Z. Serena's Pucci dress had ridden up above her waist, and her lacy blue underwear was showing. Serena propped herself up on her elbows and wiped the lipgloss scum out of the corners of her mouth. She pulled down her dress. "What time is it?" she said. Chuck glanced at her. "Time for us to take off our clothes and get in bed," he said impatiently. He'd been waiting long enough.
(von Ziegesar 2003, p.134).

Further situating Gossip Girl within the post-feminist moment is its similarity to Sex and the City (Bushnell 2002) - a quintessential girl power book turned TV series and turned movie. As well as sharing the locale of New York city, both Gossip Girl and Sex and the City portray a type of femininity (albeit of different ages) associated with the flourishing of female sexual and economic freedom under neo-liberal capitalism. In a critique of this trend, Astrid Henry claims that Sex and the City's 'vision of female empowerment is severely limited by the fact that all four of its protagonists are white, heterosexual, thin, conventionally attractive and, importantly, economically well off' (Henry 2004, p.70). She could well be describing Gossip Girl's alpha female characters, who neatly conform to this typology.

Another key feature of this post-feminist sensibility is the role digital technologies play in enabling female agency and power. A number of studies concerning girls' use of information and communication technologies reveal the alignment of success and 'coolness' with digital mobility and connectedness (Gannon 2008, p.366; Weber \& Weber 2007, p.59). These observations resonate with the work of girl studies scholar, Anita Harris, who notes that participation in the virtual circuits of information technology is a key feature of being a can-do, in-control young woman in the twenty first century (Harris 2004, pp.128-9). Being a savvy and switched-on teenage girl requires technological capital. It means having the latest camera phone and a presence on social networking sites like MSN, Facebook and MySpace. The structure and premise of the Gossip Girl series suggest a keen awareness of the importance of the latest technological trends in shaping young people's sense of identity and community. It is a book about a blog that constantly reminds the reader of this fact. By including pages that mimic the layout and look of a blog page (a toolbar runs across the top of the page, as does a web address), the books encourage readers to move beyond the page, onto the net, and into the screen. This tendency toward incorporating the visual language of the computer screen within the pages of teen fiction is not unique to Gossip Girl, having been observed as a feature of 'computer-and--novels' for teenagers (Harris cited in Mallan 2006, p.9). Gossip Girl is different to these texts in that its purpose is not necessarily to appeal to young readers of cyber literature; rather, it uses these stylistic devices to reflect the pervasiveness of new media in teenagers' modes of interaction and the increasing prevalence of communication technologies (iphones, 
blackberries, laptops, mobiles, MP3 players) as necessary 'lifestyle' accessories.

\section{Transmedia Storytelling}

In light of the key role that information technologies play in the manifestation and imagining of the post-feminist subject, Henry Jenkins' notion of 'transmedia storytelling' is useful in understanding the shifts in how teenagers engage with young adult texts like Gossip Girl. In an era of media convergence, he argues that

\begin{abstract}
younger consumers have become information hunters and gatherers, taking pleasure in tracking down character backgrounds and plot points and making connections between different texts within the same franchise. And in addition, all evidence suggests that computers don't cancel out other media; instead, computer owners consume on average significantlymore television, movies, $C D s$, and related media than the general population.
\end{abstract}

(Jenkins 2003, p.1).

Margaret Mackey has identified a similar phenomenon in writing about children's literature, noting that it is becoming increasingly common to read 'outside the book' as part of the literary experience (Mackey 2004, p.18). Readers of Gossip Girl are constantly reminded of the series' virtual dimensions though the recurrent brandishing of its web address (gossipgirl.co.uk) across the books' pages. In this way, Gossip Girl draws the reader from the immersive experience of the novel into another immersive environment, that of cyberspace.

Jenkins also highlights a growing tendency toward the co-creation of media content across the industries of film, advertising, novels, comics, television and alike. Certainly, Gossip Girl appears to conform to this trend having been conceived from the outset as a capital venture to be realised in a number of commercial contexts: book, web, and television (Pattee 2006, p.155). This type of arrangement moves away from a model where novels are adapted to the screen, and whereby the novel is configured as the 'original' from which subsequent versions are derived (Geraghty 2008). Like its predecessor Sex and the City, Gossip Girl actively moves beyond the realm of literature to inhabit an intertextual circuit of meaning that traverses media forms. It is a successful television program produced by Josh Schwartz of $O C$ fame. Its stars grace the pages of gossip and fashion magazines. The Internet enables instant access to the Gossip Girl blog on which the book is based, as well as a slew of other information in the form of book reviews, fan blogs, celebrity gossip and alike. The novels in the Gossip Girl series are full of references to designer and lifestyle brands, which also situate them in the realm of advertising.

In one sense, Gossip Girl can be understood in terms of Guy Debord's media spectacle. According to Debord (1994), the spectacular and dazzling array of representations and signs that constitute consumer society alienate the subject. In the society of the spectacle identified by Debord, images and commodity signs replace human experiences and relations. In this reading, Gossip Girl could be said to portray an 'unrealistic' representation of teen girlhood, an inaccessible ideal that is not like 'real life', hence alien to a majority of readers. Questioning this viewpoint, Pattee argues that even though young readers might not identify with the wealthy and privileged characters portrayed in the books, and whose lifestyles would be impossible to emulate, they may, nevertheless, take pleasure in the fantasy of getting a taste of this rarefied world, identifying instead with the 'wanna be' character of Jenny Humphrey (Pattee 2006, p.167). I suggest something altogether different could be occurring. The process of identification need not reside in a fantasy world or a certain character, but with the idea that regular girls can emulate the characters in Gossip Girl through their own encounters with technology. As the transmedia experience suggests, the spectacle takes on new meaning as we become immersed within technologies. This experience, characterised by 'immersion, immanence and immediacy', is central to Baudrillard's notion of integral reality (Baudrillard 2005a, p.31).

\section{Integral Reality and Gossip Girl}

Baudrillard's notion of integral reality advances his earlier ideas around simulation and hyperreality, which argue that signs have replaced reality as the dominant mode of conceptualising the world (Baudrillard 1981, p.2). In this current phase, reality has become virtualised, filtered 
through channels of digital media and communication so that all aspects of society and human relations are made transparent, knowable and visible through our encounters with, and immersion in, the digital media sphere (Baudrillard 2005a, p.17). One aspect of the multimedia Gossip Girl experience that is emblematic of the operations of integral reality is the way it confuses the distinctions between the observer and the observed. Just as teenage consumers survey the Gossip Girl world in books, on television and online, so too are they potentially being watched, monitored by surveillance cameras in urban spaces like the shopping mall, the train station and the fast-food franchise. Webcams take things a step further, bringing the camera into the home and documenting the private goingson of individuals, which are then relayed in real time across computer networks. It seems that the whole world can be visualised, making everyone a star of the screen whether by choice or accident. Being filmed at any time and in any place, Baudrillard argues, remakes individuals as often unknowing 'actors in the performance' (1996, p.26). It is this crossing-over of the viewer into the screen that creates a hyper or excessive reality by eroding the division between what exists inside and outside the screen (Baudrillard 1996, p.28). It is common practice to record everyday events and actions using personal communication devices like camera phones. This footage can be subsequently posted on a global forum such as YouTube or circulated via mobile phone networks. Internet programs like Google Street offer images of cities and suburbs, and in doing so, eradicate the need to be geographically present in a place to immediately view it and its inhabitants. In this respect, what the Gossip Girl reader may identify with is not just the fantasy offered by the exclusive, consumer-laden world depicted in the novels, but a virtual space where they may be watched and 'blogged about', just like the rich kids of New York's Upper East Side.

Even if Gossip Girl's teenage readers can not afford the same luxuries as Blair, Nate or Serena, they can relate to a world characterised by digital information and communication systems that enable ordinary individuals to participate in creating, disseminating and exchanging content via the World Wide Web (Kearney 2006). It has been noted that Gossip Girl was one of the first shows to have 'succeeded primarily on the Internet', with limited success on television but recording huge numbers of downloads (Pressler and Rovzar 2008). This observation suggests that Gossip Girl speaks to a young and tech-savvy audience who are active in determining the conditions under which they consume media. In as much as teenagers are subject to the surveillance aspects of new media technologies, many are also using digital communication devices in creative ways. 'We are all Gossip Girl!', proclaim Jessica Pressler and Chris Rovzar in a recent feature for New York Magazine (2008). By having access to technologies of surveillance and communication (like the camera phone and the Internet), readers can emulate Gossip Girl. Young adults can establish their own blogs, post video footage of their friends and family on YouTube or document their antics on social networking sites. Teenagers and their cliques become instant stars of the screen. Most significantly, as Natasha Giardina argues, 'the current shift towards amateur content creation has the potential to change the balance of power in cyberspace, and as the research shows, young people are at the vanguard of this revolution, creating not only content, but also the associated literacies and codes of behaviour that accompany it' (Giardina 2006, p.86).

Another way that the Gossip Girl novels speak to young women situated within the circuits of technology is by encouraging the reader toward multimedia engagements as a way of finding out more about the show and its characters, to access more information and insider gossip, and in turn get closer to finding out what 'really goes on' in the on and off screen lives of its stars. On the official TV show's website, fans can download music from the series and send questions to the show's producer. They can source episode synopses, cast bios, photo galleries and message boards. The blog found in the novels isn't mere fiction, but a virtual presence that adds another dimension to, or point of engagement with, the story and its characters. Readers can immerse themselves in Gossip Girl's world by entering the Upper East Side in Second Life. And yet there is more. The official book site for the show provides further information on the series and the author, amongst other things. There are fan sites, too, that provide comprehensive facts about the characters, as well as adopt the role of tabloid magazine. Here you will find 
insider gossip about Gossip Girl's stars - where they were spotted and with whom. You can also witness celebrities without makeup, walking their dogs, wearing track pants. It is made all the more 'real' to us by the instantaneous nature of much online exchange.

I argue, therefore, that what is being consumed by fans of Gossip Girl is not only the content and narrative of its various texts, but access to a perceived hidden reality. Baudrillard reasons that the abundance of information generated by the mass media, as evidenced in the case of the Gossip Girl franchise, leads to a kind of 'forced visibility' when 'everything is given to be seen, we discover that there is nothing left to be seen' (Baudrillard 2003, p.174). Could it be that Gossip Girl bombards us with too much information? The seemingly infinite amount of content devoted to this phenomenon ensures that the fun doesn't stop when the reader finishes the book or turns off the TV after watching the final program in the series. It need never end. This hypervisibility - where everything is immediate, immanent, knowable and accessible - may contribute to the anxiety concerning post-feminist girlhood, to the extent that access to virtual spaces and information risks leading to teenage girls knowing 'too much'. At the same time, being subject to an excess of information can result in a situation where nothing is left to the imagination, nothing new or novel can happen, and nothing that the creators throw at us seems surprising anymore. As noted by Pressler and Rovzar (2008), the first 13 episodes of the Gossip Girl television series have 'already included a pregnancy scare, a marriage proposal, an attempted rape, a lost virginity, a near-deadly accident, a divorce, a suicide attempt, multiple thefts, blackmail, a drug addiction, a threesome, at least two counts of breaking and entering, and an eating disorder'. When every possibility is exhausted, when all scenarios have been imagined and played out, the potential for surprise is all but eradicated. Baudrillard sees this excess of meaning as a kind of violation, in that any power that the text might have had to generate fantasy or illusion is shattered when everything is made visible to us. including Gossip Girl's portrayal of the sex and shopping lifestyle of rich teens - might not simply be a response to a perceived violation of the young female body, but a response to the technologies via which these representations circulate - circuits often outside of parental control. As Kerry Mallan suggests, 'new media technologies are often seen as the betes noirs of children's literature by some parents, teachers, and politicians who fear that digital media will lure children away from reading books and result in a generation of asocial technophiles and hackers' (Mallan 2006,p.9). Yet given the growing tendency toward transmedia storytelling, which encourages reading across a variety of textual sites, children's rejection of books in favor of computers is no longer a parent's sole concern. In this paper I have argued that we need to consider texts, their circulation and consumption, in light of the immediate and immersive digital technology experience that characterises the information age. Young adults' engagements with communication technologies make it harder for guardians to police the texts they encounter. With a proficiency in adopting and using the latest digital devices and applications, teenagers are often a step ahead of the adult and institutional gatekeepers responsible for regulating their access to information (Turow 2002, p.220). Part of the moral panic generated by novels like Gossip Girl is a product of concern over what happens when girls are immersed in an integral reality - positioned as both observer and observed, consumer and consumed - and the potential shifts in traditional adult/child power relations that may ensue when girls 'know too much'. Parents are likely also to be worried about who might have access to their children as they appear on the screen in CCTV footage, on camera phones and social networking sites, which often contain publicly available digital photos and personal details. When teenage fiction like Gossip Girl is theorised in the context of integral reality, it would appear that the access to, proliferation and excessive circulation of the signs of sex as inscribed on the teen body are as much a cause for anxiety as what is being depicted in these texts.

\section{Conclusion}

The panic and disapproval generated around the sexualisation of young women across a variety of media- 


\section{REFERENCES}

Baudrillard, J. (2005a) The Intelligence of Evil or the Lucidity Pact. Oxford \& New York, Berg.

Baudrillard, J. (2005b) 'The violence of the virtual and integral reality', International Journal of Baudrillard Studies 2, 2, 1-16.

Baudrillard, J. (2003) 'The violence of the image and the violence done to the image', in V. Grace, H. Worth \& L. Simmons (eds) Baudrillard West of the Dateline, Palmerston North, Dunmore, pp.171-181.

Baudrillard, J. (1996) The Perfect Crime. London $\&$ New York, Verso.

Baudrillard, J. (1994) Simulacra and Simulation. Michigan, University of Michigan Press.

Brown, J.D, Steele, J.R \& Walsh-Childers, K. (eds) (2002) Sexual Teens, Sexual Media: Investigating Media's Influence on Adolescent Sexuality, Mahwah, L. Erlbaum.

Bushnell, C. (2002) Sex and the City. London, Abacus.

Debord, G. (1994) The Society of the Spectacle. New York, Zone.

Durham, M.G. (2008) The Lolita Effect: Media Sexualization of Young Girls and What We Can Do About It. New York, Overlook.

Gannon, S. (2008) 'Twenty-four seven on the computers: girls, ICTs and risk', Gender and Education 20, 4: 361-373.

Geraghty, C. (2008) Now a Major Motion Picture: Film Adaptations of Literature and Drama, Lanham, Rowman \& Littlefiled.

Giardina, N. (2006) 'We enter a time of calamity: informed and "informated" youth inside and outside young adult fiction', Papers: Explorations into Children's Literature 16, 2: 82-89.

Hall, A.C. \& Bishop, M.J. (eds) (2007) Pop-porn: Pornography in American Culture. Westport \& Oxford, Praeger.
Harris, A. (2004) Future Girl: Young Women in the Twenty-First Century. London \& New York, Routledge.

Henry, A. (2004) 'Orgasms and empowerment: Sex and the City and the third wave feminism', in K. Akass \& J. McCabe (eds) Reading Sex and the City. London \& New York, I.B.Tauris, pp.65-82.

Kearney, M.C. (2006) Girls Make Media. New York, Routledge.

Mackey, M. (2004) 'Reading outside the book', Papers: Explorations into Children's Literature 14, 2, 18-27.

Mallan, K. (2006) “"Cutting it” in new times: the future of children's literature', Papers: Explorations into Children's Literature 16, 2: 5-16.

Mazzarella, S.R. \& Pecora, N.O. (eds) Growing Up Girls: Popular Culture and the Construction of Identity. New York, Peter Lang.

McRobbie, A. (2004) 'Post-feminism and popular culture', Feminist Media Studies 4, 3: 255-264.

McRobbie, A. (2007) 'Top girls? Young women and the post-feminist sexual contract', Cultural Studies 21, 4-5: 718-737.

Jenkins, H. (2003) 'Transmedia storytelling', Technology Review (online), January 15. Retrieved: 9 May 2008 from http://www. technologyreview.com/printer_friendly_article. aspx?id=13052.

Kline, S. (1993) Out of the Garden: Toys, TV, and Children's Culture in the Age of Marketing. London \& New York, Verso.

Pattee, A. (2006) 'Commodities in literature, literature as commodity: a close look at the Gossip Girl series', Children's Literature Association Quarterly 31, 2: 154-175.

Pressler, J. \& Rovzar, C. (2008) 'The Genius of Gossip Girl', New York Magazine (online), 21 April. Retrieved: 29 April from <http://www.printthis. 
clickability.com $/$ pt/cpt?action $=$ cpt\&title $=$ The + ge nius + of + Gossip + Girl $>$

Reist, M.T. (2008) 'The pornification of girlhood', Quadrant 52, 7/8: 10-16.

Rush, E. \& La Nauze, A. (2006) 'Corporate paedophilia: sexualization of children in Australia', The Australia Institute, Discussion paper 90: 1-53.

Turow, J. (2002) 'Family boundaries, commercialism, and the internet, a framework for research', in J. Turow \& A. Kavanaugh (eds) The Wired Homestead, Cambridge: Mass, MIT Press.

von Ziegesar, C. (2003) Gossip Girl. London, Bloomsbury.

Weber, S. with Weber, J. (2007) 'Technology in the everyday lives of "tweens", in S. Weber \& S. Dixon (eds) Growing Up Online: Young People and Digital Technologies. New York, Houndmills, Basingstoke, Hampshire, Palgrave Macmillan.
Wolfe, N. (2006) 'Young adult fiction: wild things', The New York Times (online), 12 March. Retrieved: 29 April 2008 from http:/www. nytimes.com/2006/03/12/books/review/12wolf. html?pagewanted $=1 \& \_r=1$

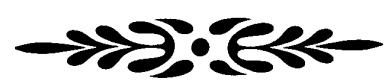

\section{BIOGRAPHICAL NOTE}

Kim Toffoletti is a lecturer in Gender Studies at Deakin University, Melbourne, Australia. She is the author of Cyborgs and Barbie Dolls: Feminism, Popular Culture and the Posthuman Body (2007, I. B. Tauris). Her research interests include post-feminism and popular culture, posthumanism, gender/technology debates and female football fandom.

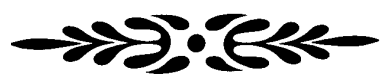

